\section{EL MITO DE DON JUAN EN EL
CINE: DE MOLIĖRE A JACQUES \\ EL MITO DE DON JUAN EN EL
CINE: DE MOLIĖRE A JACQUES WEBER}

\section{DON JUAN'S MYTH IN CINEMA: FROM MOLIĖRE TO JACQUES WEBER}

\author{
Carmen Becerra Suárez \\ Universidad de Vigo \\ cbecerra@uvigo.es
}

\begin{abstract}
From its birth in Spain in the 17th century, the myth of Don Juan has been explored through a diversity of genres, approached by numerous artists, from a wide range of perspectives and artistic expressions, interpreted by philosophers and studied by scientists. This article analyzes the modifications that the mythic scenario displays in Jacques Weber's cinematographic version, taking into account the specific issues related to the shift of language, from literature to cinema, alongside other aspects of similar interest. Furthermore, given the fact that the study case is the result of a film transposition from a particular literary text, in this case Molière's account of Don Juan, we will analyse, first and foremost, the suitability of the original literary text to the mythic discourse.
\end{abstract}

KEY WORDS: Myth; Don Juan; film adaptation.

A lo largo de su dilatada historia, el mito de Don Juan ha sido vertido en muy diversos moldes (el teatro, la poesía, la novela, la ópera, la danza, el cine...), y si bien es cierto que unos han sido preferidos a los otros, probablemente como consecuencia de determinadas características internas e inalienables del personaje protagonista, es estadisticamente demostrable que Don Juan ha frecuentado con mayor asiduidad el teatro que ningún otro género, si bien algunas de las versiones llamadas "mayores", por su importante papel en la transmisión y reorientación del mito, no son teatrales; pienso, por ejemplo, en la versión narrativa de Hoffmann, de importancia capital para la interpretación romántica. Tampoco el cine ha permanecido ajeno al tema, aunque ha de reconocerse que las versiones cinematográficas poco o nada han aportado a la evolución del mito si, dejando a un lado la mayor o menor calidad del film, consideramos los frutos que de ellas han surgido.

Si bien es cierto que en uno de los diccionarios más prestigiosos sobre el mito de Don Juan (Brunel, 1999) podemos leer, en la entrada "Cinéma, Don Juan au", afirmaciones como la que sigue":
RESUMEN: Desde su nacimiento en el siglo XVII español, el mito de Don Juan ha sido vertido en diferentes géneros, abordado por numerosos creadores, desde perspectivas y expresiones artísticas diversas, interpretado por filósofos y estudiado por científicos. Este artículo analiza las modificaciones que el escenario mítico presenta en la versión cinematográfica de Jacques Weber, teniendo en cuenta, además de otras causas de semejante interés, las relacionadas con el cambio de lenguaje: de la literatura al cine. Pero además, como el film estudiado es el resultado de la transposición fílmica de un texto literario particular, en este caso la versión donjuanesca de Molière, se analiza, en primer lugar, la adecuación al discurso mítico del texto literario de partida.

PALABRAS CLAVE: Mito; Don Juan; adaptación cinematográfica.

Bien que l'histoire du cinéma soit jalonnée de séducteurs célèbres et que le cinéma français, par exemple, soit fortement marqué par la tradition littéraire libertine des XVII et XVIII siècles, le theme de Don Juan a, paradoxalement, semblé inspirer peu les cinéastes. Les apparitions à l'écran de Don Juan étaient peu nombreuses (J.-F. Hans, 1999, 185).

un recuento simple de tan sólo las versiones occidentales, excluyendo del mismo aquellas en las que el protagonista no es Don Juan, sino un personaje donjuanesco, o las que giran en torno a la figura de Casanova, o personajes dieciochescos, como el creado por Choderlos de Laclos (Les liaisons dangereuses, 1782), y aquellas otras que presentan un donjuán femenino - una doña Juana-, prueba que el tema ha interesado a los cineastas casi tanto como a los escritores, tal y como afirma Luis Miguel Fernández en su excelente y documentado trabajo titulado Don Juan en el cine español.

Convendría, sin embargo, antes de entrar en materia, recordar que nos situamos no sólo ante una adaptación particular, la realizada por Jacques Weber en este caso, 
sino también ante la transposición de un código -el literario- a otro -el fílmico- de un conjunto de rasgos, los de un mito literario -a los que el estructuralismo Ilama "invariantes"-, que se han mantenido inalterados a lo largo de varios siglos de historia ${ }^{2}$. Así pues, como sostiene Luis Miguel Fernández, el análisis de las recreaciones fílmicas de Don Juan ha de referirse necesariamente a "como mínimo dos estructuras significativas: la del muthos de la tradición aristotélica, es decir, el personaje mítico como un relato o historia en sí mismo, y el de un discurso literario específico en el que el anterior se encarna y que puede contener múltiples variaciones con respecto al primero" $(2000,43)$.

En definitiva, en todo proceso de adaptación o transposición fílmica de un mito literario deben ser considerados tres niveles de análisis:

1) En el primer nivel se analiza la adecuación al discurso mítico que, en este mito en particular, se resume esencialmente en el mantenimiento de los rasgos específicos o invariantes.

2) En el segundo nivel se analiza la adecuación al texto literario de partida; dicho de otra manera, la permanencia de los elementos fundamentales de la historia, el mantenimiento de los personajes principales, el orden de las escenas (en los textos dramáticos) y el tratamiento de las coordenadas espacio-temporales, entre otros aspectos de, quizás, de menor interés.

3) En el tercer nivel se sitúan los factores que provienen del cambio de género, o de modo de expresión, si queremos evitar la polémica nominalista, de la literatura al cine. Aquí intervienen aspectos de diferente naturaleza e importancia: desde los relacionados con, por ejemplo, la enunciación o el tratamiento tempoespacial, hasta cuestiones aparentemente menos relevantes como las derivadas de la elección de determinado actor o actriz, entre otras.

En este marco metodológico es donde sitúo mi aproximación al análisis del film de Jacques Weber, titulado Don Juan (1998), resultado de la adaptación de la comedia de Molière, Dom Juan ou Le Festin de Pierre, publicada en 1665.

ARBOR Vol. 187748 marzo-abril [2011] 259-267 ISSN: 0210-1963
Nos hallamos, siguiendo la terminología de Lubomir Doležel, ante una transducción, concepto que incluye fórmulas y fenómenos muy diversos, tales como la inclusión de un texto en otro, la transformación del género original de una obra, la traducción, o la transducción fílmica de un hipotexto; este último proceso, como señala Darío Villanueva, "resulta especialmente característico y fecundo en nuestra sociedad de la comunicación y la información" $(2008,81)^{3}$.

Así pues, en este caso particular, el texto dramático de Molière, Dom Juan ou Le Festin de Pierre (1665), será el hipotexto de la película Don Juan, hipertexto realizado por Weber en 1998. Ahora bien, si tenemos en cuenta que la obra de Molière es ya un hipertexto de versiones anteriores caeremos en la cuenta de que cualquier versión donjuanesca tiene como hipotexto el discurso mítico original, caracterizado por la presencia de determinadas invariantes.

En el mito de Don Juan, y sigo aquí a Jean Rousset (1978), los rasgos permanentes del escenario donjuanesco, rasgos que le identifican y lo diferencian de cualquier otro mito, es decir, las invariantes, son: 1) el muerto, 2) el grupo femenino, y 3) el héroe. La interrelación entre ese trío de invariantes genera una gran riqueza de posibilidades. Así por ejemplo, el rasgo número uno, el muerto, tiende a privilegiar a una de las mujeres del grupo, aquella que está en relación directa con el muerto y el héroe: la hija del muerto, quien, ligada simultáneamente a los tres soportes del relato, aparece como la pieza central de esa trama triangular. Son muy diversas las opciones que los autores han ido tomando respecto de este personaje: desde su tratamiento como una mujer más entre otras muchas (papel en el drama fundacional atribuido a Tirso de Molina), hasta su desaparición (opción, por ejemplo, de Molière), pasando por la conversión en la auténtica protagonista del drama (en las versiones románticas). La supresión de uno de estos rasgos, o lo que es lo mismo la aparición de "variantes", origina un desequilibrio estructural que da lugar a un proceso de desmitificación; dicho de otra manera, el mito se desmitifica y adquiere otra naturaleza diferente. La desmitificación puede venir provocada no sólo por los cambios que se produzcan en las interrelaciones de esas tres invariantes, sino también por transformaciones que afecten a cada una de ellas en particular, y que alteran la relación respecto del conjunto ${ }^{4}$. 
Pues bien, los estudiosos de la trayectoria donjuanesca saben que se debe a Molière la primera recuperación del mito. A la lección teológica del fraile mercedario le sigue un racionalismo escéptico que preludia el ambiente ilustrado. Don Juan habia llegado hasta el dramaturgo francés, a través de los Comediantes dell'Arte, en un estado casi caricaturesco. Molière lo rescribe, lo transforma y lo salva de la degradación total. La comedia, cuya acción se desarrolla en Sicilia, supone la combinación y reelaboración de elementos procedentes de varias fuentes. Aunque no está demostrado que Molière ignorase el original de Tirso, parece que conocía perfectamente las tragicomedias de sus contemporáneos Dorimon (Le Festin de Pierre ou le fils criminel, Lyon, 1659) y Villiers (Le Festin de Pierre ou le fils criminel, París, 1660). El análisis del texto prueba además que había leído, o visto, algunos de los "escenarios" donjuanescos de los comediantes italianos, hecho que no resulta extraño dada su común utilización de un mismo teatro -Le Petit Bourbon- durante algunos años; es indudable que determinados elementos de su obra proceden de esta fuente ${ }^{5}$.

Molière moderniza al personaje y adapta su conducta y su carácter a sus propios intereses (por ejemplo, la crítica de costumbres), y a determinadas tendencias, o ideas, muy influyentes en el momento. Aunque estamos todavía muy lejos del libertino degenerado y perverso que pocos años después nos proporcionarán Rosimond (Le Nouveau Festin de Pierre ou L'athée foudroyé, Paris, 1669) y Shadwell (The libertine, Londres, 1676), las ideas libertinas, a las que el propio Molière no fue ajeno $0^{6}$, subyacen en muchas de las actitudes y reflexiones que encontramos en don Juan. Así por ejemplo, cuando harto de los sermones de Sganarelle, le ordena que se calle, el criado le responde:

SGANARELLE: ¡Dios me libre de sermonearos, señor! De ninguna manera. Sabéis de sobra lo que hacéis, y si no tenéis fe en nada, vuestras razones tendréis para ello. Pero es que hay, señor, algunos majaderos en este mundo que son libertinos sin saber por qué y que alardean de ser descreídos porque se figuran que esto es de muy buen tono. $Y$ si yo tuviese un amo de esa calaña le diría cara a cara y claramente, porque no tengo pelos en la lengua: ¿Así os atrevéis a desafiar al Cielo y no tembláis al mofaros de lo más santo que existe? ¿Podéis, gusano miserable, galán de alfeñique -así le diria al amo ese de que hablábamos- podéis burlaros de todo lo que los demás reverencian? (97)7.
Don Juan, que ha perdido en pasión y generosidad, respecto al original tirsiano, pero que ha ganado en inteligencia, actúa premeditadamente y hace profesión declarada de hipócrita:

DON JUAN: Ahora nadie se avergüenza de esto. La hipocresía es un vicio a la moda, y los vicios a la moda han pasado siempre por virtudes. El papel del hombre de bien es el más fácil de representar. En nuestros días el oficio de hipócrita tiene portentosas ventajas, y es arte cuya impostura siempre obtiene el respeto, pues aunque llegue a ser descubierta, nadie se atreve a publicarla. Los demás vicios de los hombres están expuestos a la crítica, y todos se atreven a atacarlos de frente y con rudeza; pero la hipocresía es un vicio privilegiado que con la propia mano tapa la boca de las gentes y goza a sus anchas de una impunidad soberana (153).

Otro de los rasgos relevantes de este don Juan es su declarado ateísmo, para la mayoría, o su descreimiento o escepticismo, para otros: al ser interrogado acerca de sus creencias responde con exclamaciones, con silencios o con frases sin terminar $y$, cuando presionado por la machaconería inquisidora de Sganarelle, se decide a contestar, su respuesta no puede ser más materialista: "Creo que dos y dos son cuatro, Sganarelle y que cuatro y cuatro son ocho" (126). Cuando la presencia de Dios se hace patente a través de la estatua de piedra, no le parece todavía prueba suficiente: "Hay algo que no acierto a comprender. Pero sea lo que fuere no existe en el mundo nada capaz de convencer mi razón, ni de conmover mi alma" (152) ${ }^{8}$. Incluso en el momento en que se produce la aparición sobrenatural del espectro quiere con su espada constatar su realidad.

Precisamente por este descreimiento que reiteradamente muestra, la presencia de la estatua del Comendador y el desafío a los muertos, con motivo de la invitación a cenar, no deja de ser algo sorprendente. Si a ello añadimos que desconocemos cuál es el vínculo del Comendador con una de sus víctimas; o dicho de otro modo, no sabemos si, como impone la tradición, el Comendador es el padre de no sabemos cuál de las mujeres ofendidas, su intervención final se encuentra débilmente motivada, creando, como señala Jean Rousset (1970, 29-36), un desequilibrio estructural al alterar la relación entre el Héroe y el Muerto. A este respecto, Carlos Feal va más allá en su apreciación al

ARBOR Vol. 187748 marzo-abril [2011] 259-267 ISSN: 0210-1963 
considerar que la acción de la estatua es algo "rayano en lo cómico" (1984, 102-103), por tratarse de un elemento mecánico y forzado, sin causa aparente. A mi juicio, la intervención de la estatua en el texto de Molière parece totalmente gratuita, pues está despojada de la función que poseía en el texto original: vengadora del honor y emisaria del Cielo. Por ello, la utilización de este personaje por Molière puede ser interpretada como una concesión bien a la tradición, bien a las imposiciones religioso-morales de la época que exigían el castigo del libertino. Por consiguiente, tanto el castigo final del protagonista, como su arrebato de generosidad en el bosque con los hermanos de Elvira (acción que humaniza al personaje) pudieran ser considerados como elementos destinados a obtener la benevolencia de público y censores ante el comportamiento y las ideas de aquel cínico en rebeldía contra la sociedad y contra Dios. En cualquier caso, si ése hubiera sido el efecto perseguido no alcanzó resultados positivos pues, como es sabido, al cabo de quince representaciones Molière fue obligado a retirar su Don Juan de escena, como exponente de libertinaje y ateísmo ${ }^{9}$.

Pese a todo, el tema, profundamente religioso en el original tirsiano, que se había hecho laico en Italia y en las primeras versiones francesas, obtiene con Molière un nuevo equilibrio: su héroe es a la vez un delincuente y un pecador ${ }^{10}$. En la comedia molieresca el Rey no comparece, frente a lo que ocurría en sus antecesoras española e italianas, pero la ley está representada por el padre de don Juan, personaje que alcanza en este texto la solemnidad de un soberano, encarnando los valores de la sociedad aristocrática que el hijo ha transgredido. Por otra parte, la justicia divina está representada por Elvira, esposa de Don Juan, no en su primera entrada en escena, reclamando a don Juan sus deberes de marido y amante, sino en la segunda, cuando las palabras de mujer enamorada se transforman en retórica devota"1:

ELVIRA: El cielo ha arrancado de mi corazón el fuego en que me abrasaba, los arrebatos desordenados de una pasión criminal (...) sólo vive en mi alma la llama de amor puro con que os amo (...) que no busca nada para sí, sino sólo de vuestro bien se ocupa [...] Este amor purisimo y perfecto me trae aqui, por vuestro bien, para haceros saber un aviso del cielo y tratar de apartaros del abismo en que os precipitáis (...) que está en vuestras manos evitarlo con un sincero arrepentimiento (146).
De este modo Molière establece los dos órdenes ante los que su Don Juan es justiciable: "Cielo a quien ofendió, leyes violadas..." (159).

Muy probablemente el momento en que de modo más claro se definen las creencias de este don Juan se encuentre en la escena segunda del acto III. La escena muestra el diálogo entre don Juan y un pobre, en presencia de Sganarelle. EI pobre pide limosna a don Juan y éste, después de mofarse de la miseria en la que vive este hombre, pese a pasar cada día de su vida rogando a Dios, le promete un luis de oro si se atreve a jurar delante de él; ante la negativa reiterada del mendigo don Juan insiste, pero el hombre está dispuesto a morir de hambre antes de cometer un pecado. Finalmente don Juan le da la moneda, pero no por amor a Dios, sino por "amor a la humanidad". El personaje, cuyo origen no está en la comedia molieresca, adquiere aquí un nuevo sentido $^{12}$. Ya no se trata únicamente de escenificar la burla y el desprecio de don Juan hacia la pobreza y la caridad ("¿cómo puede ser que un hombre que reza de la mañana a la noche no tenga suerte en todos sus negocios?" [126], dice don Juan), sino que además intenta que el pordiosero jure hipócritamente para obtener el dinero del que está necesitado para vivir, aunque sabe bien que no por eso va a perder su fe ("en nuestros días el oficio de hipócrita tiene portentosas ventajas", [153], dice don Juan). La escena, tantas veces y por tantos estudiosos comentada, revela algunos de los rasgos claves del pensamiento libertino de la época: ateísmo, racionalismo, burla al sistema, ventajas sociales y personales derivadas de la hipocresía.

En suma, si tenemos en cuenta los siguientes datos: 1) frente al contenido tradicional, en esta versión las escenas amorosas sólo ocupan la cuarta parte de la obra; 2 ) los afanes seductores de don Juan, por razones diversas, quedan aquí casi siempre insatisfechos; y 3) se analice como se analice la intervención de la Estatua del Comendador, y por tanto el castigo de don Juan, presenta en esta obra una debilidad extrema, podemos llegar a la conclusión de que Molière utilizó un tema popular como pretexto para, manteniendo determinados rasgos tradicionales, llevar a cabo una crítica de la sociedad de su tiempo desde una posición social, filosófica y teológica que caracterizaba a los libertinos.

Estrenada en Francia en el año 1998, la película Don Juan de Jacques Weber, coproducción franco-hispano-alemana 
que cuenta en el reparto con dos conocidas actrices españolas, Ariadna Gil y Penélope Cruz, es una adaptación ciertamente particular de la pieza molieresca ${ }^{13}$. El discurso fílmico presenta una estructura narrativa moderna y libre, guiada esencialmente por la independencia de su director quien, como él mismo afirma, lo que pretende destacar básicamente en la cinta es el espíritu de rebelión, de transgresión, de quebranto de las leyes que dan supremacía al hombre y a su libre albedrío. Weber suprime escenas (la primera del Acto I, o la tercera y la quinta del Acto $V$, entre otras) y provoca desplazamientos significativos respecto al texto adaptado. Veamos sólo los que juzgo más relevantes:

En primer lugar, altera el orden de las escenas de la comedia. La escena del pobre, en la que nos detendremos enseguida, es la segunda de la primera secuencia del film (en Molière se ubica en el Acto III, Escena segunda), y los hermanos de Elvira aparecen inmediatamente después (en Molière entran en escena avanzada la obra, en el Acto III, Escena tercera). Estas acciones, desplazadas de su lugar original, permiten al espectador conocer, desde el principio, la ideología del libertino, mostrando a un don Juan irremediablemente perdido, de cuya conducta no es esperable enmienda y cuyo destino no alberga ninguna duda.

La película de Weber mantiene la comentadísima escena con el pobre del texto de Molière, pero su situación en el discurso (después de una brevísima escena de diálogo entre Don Juan y Sganarelle, mientras huyen a caballo en la primera secuencia) y la elección del actor que interpreta el papel de pobre alteran sustancialmente su significado. El discurso fílmico arranca con una secuencia en la que Don Juan y Sganarelle huyen de los hermanos de Elvira que les persiguen; detienen su carrera en una aldea abandonada, donde sólo hay cadáveres y polvo, y es ahi donde tiene lugar el encuentro con el pobre. Es decir, Weber proporciona en primer lugar al espectador las ideas de don Juan, sus creencias, aquello en lo que basa su conducta, para más adelante, ofrecer su otro rasgo, el de seductor. Parece interesar más al realizador el pensamiento, la ideología de don Juan, que las acciones sobre las que descansa su fama: la conquista de mujeres. Acierta el director, porque es indudable que ésa era también la intención del dramaturgo francés, el sentido que quiso darle a su don Juan: cerebral, inteligente, filosófico. Sin embargo, a mi juicio, Weber se equivoca en la elección del actor; el personaje del pobre está interpretado por un niño de corta edad; la consecuencia inevitable es que la reacción del personaje ante la oferta de don Juan resulte para el espectador totalmente inverosímil: difícilmente un niño, y menos aún muerto de hambre, puede poseer principios tan arraigados como los que éste muestra, principios, por otra parte, que se acomodan mal con la actitud descarada y chulesca que adopta con los caminantes; la escena, así tratada, pierde casi todo el sentido original.

En segundo lugar, Weber modifica el espacio de la historia que, al margen del escenario real en que fue filmada, se desarrolla en el sur de España (en Molière, el espacio es Sicilia); este desplazamiento espacial se logra mediante la introducción, sobre todo por banda sonora, de determinados elementos que sitúan la obra, y por tanto a su protagonista, en el ámbito geográfico y cultural donde fueron creados; así, por ejemplo, los asistentes a la misa funeral por el alma de los muertos en el naufragio del barco de don Juan cantan sus rezos en español; y la fiesta nocturna que se celebra en la aldea de pescadores está ambientada con música, cante y baile flamencos.

Pero no son estos los únicos cambios que contiene el film, podemos señalar también otros audaces desplazamientos espaciales que rebelan, no capricho o arbitrariedad, sino una muy meditada puesta en escena comportando una carga semántica añadida que es preciso interpretar; analizaré brevemente uno de ellos situado al comienzo del film.

La acción de la primera secuencia no ocurre en las galerías de un palacio, como en la comedia de Molière, sino en un valle árido, desierto, devastado y polvoriento. El paisaje es aquí una prolongación del personaje, un signo que lo representa y habla de él al espectador; una aproximación a la subjetividad del personaje mediante una representación del espacio altamente simbólica ${ }^{14}$. Don Juan se muestra como un hombre en decadencia, un libertino fatigado, su final está próximo, sabe que la muerte le acecha, todo a su alrededor evoca destrucción; su vida, como su castillo, que más adelante veremos, no es más que una ruina. El sentido que alcanza inmediatamente el personaje, producto de sus acciones, sus palabras y de la puesta en escena, es ratificado por la coherente elección del actor protagonista, sin duda lo primero que Ilama la atención, porque Weber no solamente dirige la película, también interpreta el papel de 
don Juan; el resultado es que nos encontramos ante un don Juan maduro y envejecido, frente a la insolente juventud y belleza del joven seductor del escenario mítico ${ }^{15}$. El arranque de la película, que con toda seguridad ha de sorprender las expectativas del conocedor del texto de Molière $y / 0$, en general, del escenario mítico, muestra al espectador la figura de espaldas de dos hombres que cabalgan por una Ilanura solitaria y árida. El paisaje, el polvo, el calor y el vestuario de estos hombres evoca inmediatamente en el espectador imágenes semejantes del cine clásico del oeste americano: ¿se trata de un símil entre la decadencia de un género y la de un mito centenario?

Sin embargo, y a pesar de todos los desplazamientos y de su moderna estructura narrativa, el film de Weber contiene algunos elementos que lo anclan en una herencia literaria perfectamente integrada en la enciclopedia cultural de los espectadores. La crítica social es uno de los temas desarrollados en el discurso, con mayor o menor relieve, desde el drama fundacional tirsiano. El tema, fundamental en la pieza de Molière, se mantiene intacto en la película de Weber. Don Juan se aprovecha de su condición de caballero, del poder que la pertenencia a una clase le otorga, para salir impune de sus delitos. El abuso de poder es uno de los motivos de la obra; aquellos que le amparan y ayudan, por acción u omisión, representan como él a la corrupta sociedad de su tiempo; la escena del baile en la aldea de pescadores, lo pone de manifiesto: con absoluto desprecio y sin la menor consideración con quien le ha salvado la vida, don Juan no sólo seduce a la prometida de Pierrot, sino que le abofetea dos veces sin que Pierrot pueda responder de otro modo más que con una sollozante indignación, casi ridícula: "Ce n'est pas bien de battre les gens", dice Pierrot gimoteando.

En general, Weber mantiene los diálogos y los caracteres de los personajes de Molière sin alteraciones. Así, por ejemplo, Sganarelle, el criado de don Juan, personaje más complejo que en el original tirsiano, su consejero, cómplice y conciencia moral, es quien cierra, en ambos textos, la obra: mendigando a la puerta de la iglesia, se lamenta de que mientras todos están satisfechos con la muerte de su amo, él es el único desgraciado, " $¡ A y$, mi salario, mi salario, mi salario!" (159). No obstante, quiebra significativamente la asociación amo-criado en el desenlace: en el discurso fílmico, Sganarelle no acompaña a su amo en su encuentro definitivo con la muerte.
Del mismo modo que algunas debilidades del texto de Molière pueden ser explicadas por una preconcebida adecuación a la estructura mítica original, la fidelidad al texto fuente (en este caso al de Molière) provocaría esa misma debilidad estructural en el film de Weber. Como manda la tradición, don Juan muere a manos del Comendador; $y$, también aquí, la muerte de don Juan se produce como resultado de la ofensa al muerto; pero, frente a lo que sucede en el texto literario de partida, no sabemos qué relación existe entre el Comendador y don Juan, o entre el Comendador y las víctimas del seductor, de manera que su intervención y su relación con el infausto destino del protagonista quedan escasamente justificadas.

Ahora bien, no todo lo que sucede en torno a la muerte de don Juan puede ser explicado por la fidelidad de la adaptación; muy probablemente la intención de modernizar el mito, de adecuarlo al receptor del siglo XX, genera en el texto de Weber una serie de variaciones muy originales que aproximan el discurso a planteamientos más realistas.

Las apariciones sobrenaturales de la muerte, en el texto de Molière, bajo las formas de Espectro vestido de mujer, de Tiempo con la guadaña en la mano y de Estatua parlante, se reducen en el film a la presencia de una sola figura: una gigantesca estatua. El lugar en donde se encuentran por primera vez la estatua del Comendador y Don Juan, 0 lo que es lo mismo, el héroe y la muerte, supone un nuevo desplazamiento espacial de gran interés. En el texto de Molière el encuentro ocurre en el mausoleo del Comendador (Acto III, Escena V); en la película, sucede durante una travesía nocturna por el mar, en un lugar indeterminado cercano a la costa: la estatua del Comendador es trasladada por mar hacia, supuestamente, el recinto donde se encuentra su mausoleo. Siguiendo la tradición mítica, Sganarelle, obligado por don Juan, formula la invitación; la estatua acepta con un movimiento de su cabeza. Ahora bien, el aparente asentimiento a la invitación de don Juan puede ser explicado racionalmente, ya que la inclinación repetida de la cabeza de la estatua podría ser en realidad el resultado de una ilusión óptica, provocada por el balanceo de la embarcación que la transporta, y no un fenómeno sobrenatural que simboliza una señal del Cielo.

También el desenlace contiene importantes variaciones a las que, en principio, podriamos otorgar la misma explicación racionalista; es decir, lo supuestamente extraordinario 
podría ser justificado por la razón. Don Juan, como en la pieza de Molière, y como en el drama fundacional, muere a manos del Comendador; pero si el dramaturgo francés, siguiendo la tradición, hace morir a don Juan, en presencia del criado, en el segundo encuentro con la Estatua (don Juan, en respuesta a su petición, da la mano a la estatua y se hunde con ella en los abismos, con gran aparato de rayos, truenos y fuego), en el film de Weber, don Juan evita la compañía de Sganarelle y se dirige solo a su encuentro; el cara a cara entre el hombre y la muerte se produce sin el apoyo de su fiel compañero. Ya en el recinto, escala trabajosamente por el andamiaje de la monumental estatua hasta la cima, sufre un desfallecimiento, cae y muere. Examinada así la acción, el desenlace no tendria nada de milagroso; no sería el Cielo el responsable de la muerte de don Juan, sino su insensatez y locura; no estariamos ante un pecador que, tras burlar las leyes de los hombres, recibe un castigo divino, sino ante un libertino y vividor cuya muerte es el resultado lógico de su desatinada vida. Sin embargo, examinado con detenimiento, el desarrollo de la acción y el lenguaje fílmico utilizado en la secuencia permiten calificar como ambiguo el significado del desenlace. Don Juan llega al mausoleo del Comendador, detenido al pie de la estatua mira hacia arriba, una cámara subjetiva con angulación picada proporciona la imagen de la cabeza y la mano de la efigie en primer plano. Una vez en la cima, si prestamos atención a las palabras que susurra don Juan ("¿Qué siento? ¡Me abrasa un fuego invisible! ¡No puedo más! ¡Todo mi cuerpo es una hoguera encendida!", palabras que coinciden exactamente con las pronunciadas por el personaje de Molière al dar su mano respondiendo a la solicitud de la Estatua), si, además, tenemos en cuenta que, tras su caída, el primer plano que muestra el rostro herido de don Juan, agonizando al pie de la estatua del
Comendador, va precedido de otro en el que de nuevo se muestra en el encuadre, muy próximo al objetivo, la colosal mano de la estatua, y recordamos el sentido que este motivo posee en el escenario mítico, podriamos afirmar que Weber proporciona con este desenlace un significado trascendente a la muerte de su don Juan ${ }^{16}$.

En suma, también aquí, como en todas las versiones míticas, las aventuras de este don Juan y su fiel criado Sganarelle manifiestan los rasgos clásicos del escenario donjuanesco, sentimientos tan universales como la libertad, el poder, el deseo, la vida y la muerte. La original versión de Weber, que no es ni una representación filmada, ni una fiel adaptación, y que ha renunciado a la utilización de cualquier truco técnico de luz, sonido o movimiento, reinterpreta y moderniza la pieza de Molière aproximándola al espectador contemporáneo. Para ello pone en escena a un héroe envejecido, que mantiene todavía un cuerpo hermoso y ávido de placer, y concede especial importancia al telón de fondo, al escenario: paisajes magníficos, devastados y desérticos, como el final de la trayectoria vital de quien los habita, o salvajes y exóticos, como las orillas de la playa o las costas rocosas recortadas por el mar donde se desarrolla la seducción de las pescadoras, Charlotte y Mathurine. La naturaleza y sus efectos en los personajes son igualmente reseñables. Recordemos, a modo de ejemplo, la furia de la tormenta que hace naufragar su embarcación, inmediatamente después de que don Juan proclame su ideario libertino (¿señal premonitoria?). Acompañado por una banda sonora musical que, en ocasiones, alcanza la altura de coro trágico, don Juan es en esta versión cinematográfica un hombre inteligente, solitario, ateo y soberbio, dominado todavía por un deseo insaciable, que camina sin miedo y sin remedio hacia su destino final.

\section{NOTAS}

1 No se dispone por el momento de un catálogo completo y ordenado de las adaptaciones filmicas del mito de don Juan. La voz cinema que contiene el diccionario de Pierre Brunel resulta poco útil por muy incompleta.

Recibido: 8 de octubre de 2008 Aceptado: 28 de marzo de 2009
2 Estoy siguiendo aquí la teoría formulada por Philippe Sellier (1984) quien agrupa las distintas realidades culturales consideradas mitos en cinco conjuntos bien delimitados. Don Juan pertenece, en la formulación de Sellier al segundo grupo: "Mitos de nuevo nacimiento" pertenecientes a la cultura occidental. Estos conjuntos contienen una serie de rasgos comunes: a) descansan sobre organizaciones simbólicas que provocan 
emociones en los seres humanos, esto es, "mueven" anímicamente al receptor; lo que les proporciona una riquísima indeterminación significativa, una polivalencia excepcional; b) se agrupan en organizaciones cerradas de estructura compleja; y c) contienen una "advertencia" metafísica; o lo que es lo mismo, enfrentan al hombre con el más allá".

3 En este mismo artículo, Villanueva muestra su sorpresa ante la falta de reconocimiento que algunos planteamientos teóricos han dado a esta práctica semiótica, tan característica de la sociedad en la que vivimos, y pone como ejemplo su ausencia entre los fenómenos de Hipertextualidad definidos por Genette en su obra Palimpsestes (1989).

4 Para un análisis detallado de la evolución del mito de Don Juan, desde su nacimiento en España hasta el siglo XX, remito a mi libro Mito $y$ Literatura. Estudio comparado de Don Juan (1997).

5 El nombre de Sganarelle es el de uno de los "zanni" de la Commedia (precisamente el personaje interpretado por Molière en escena). Es Sganarelle quien cierra la comedia lamentándose porque ya todos están vengados, y por ello contentos, menos él que no ha recibido su paga: "Mes gages, mes gages!", dice Sganerelle. Éste es también el final de Convitato de pseudo-Cicognini y de los "escenarios" que conocemos a través de las notas del actor Domenico Biancolelli. Una reproducción de esas notas se encuentra en Macchia (1978, 151165).

6 Así lo señala, entre otros muchos estudiosos de la obra de Molière, Jacques Guicharnaud: "Nous savons que Molière a connu les libertins de son temps et nous pouvons penser que le libertinage a été pou lui au moins une tentation intellectuelle, peut-ètre même la seule philosophie selon son coeur" $(1963,260)$.

7 Cito por la edición de Espasa-Calpe, Colección Austral, Madrid, 1980.

8 A juicio de Gerard Defaux, Molière utiliza el tema de Don Juan para llevar a cabo una sátira social: "Sa comédie est donc (...) double démystification. Démystification d'abord de la societé qui denonce Dom Juan et qui le poursuit, impitoyable mise à un de son essentielle mauvaise foi, de la fausseté de ses attitudes et de ses réthoriques, de son impuissance, de ses peurs et de ses superstitions, de ses valeurs décisoires. Illusoires et corrompues. Mais aussi démystification du libertin lui même, de l'image exagérément horrible que la societé s'en fait" $(1980,144)$

9 Será necesario esperar a 1813 para que se reedite el texto original; y a 1841 para que la comedia original sea de nuevo representada. Véase Robert Horville, 1972, 67.

10 En estas versiones, el personajeprotagonista ha de dar cuenta de sus actos sólo ante el Rey, personaje inexistente en el texto de Molière, pues es tratado como mero delincuente, como un mero violador de las leyes sociales.

11 Elvira, cuyo antecedente está en el personaje de Leonora del escenario anónimo L'Ateista Fulminato, escrito alrededor de 1650, introduce en el tema algo que faltaba y que la ópera retomará. Elvira es el gran amor de don Juan, motivo que alcanzará su más elevada expresión y su verdadero desarrollo en las versiones románticas. Véase Macchia, 1978, 119-135.

12 Este personaje, cuyo antecedente es un "romito" que pide limosna al conde Aurelio y sólo obtiene su desprecio y sus burlas, en una escena del anónimo L'Ateista fulminato, aparece como "peregrino" en las obras de Villiers y Dorimond. La figura del mendigo será recogida por Baudelaire en su poema "Don Juan en los infiernos", incluido en Las flores del mal.

13 La película, debut como director del actor Jacques Weber, Ilega a las pantallas españolas dos años más tarde, en el año 2000.

14 Weber se sitúa con estos procedimientos en la estela iniciada por el Free Cinema británico, la Nouvelle Vague francesa o el Neorrealismo italiano.

15 En la tradición donjuanesca, los primeros donjuanes viejos aparecen en obras escritas en la segunda mitad del siglo XIX, como consecuencia de la reacción antirromántica. Véanse, por ejemplo, la obra de Gustave LeVavasseur, Don Juan Barbon (1848), o la de Jules Viard, La Vieillese de Don Juan (1853); esta última continúa la obra de Molière allí donde aquella había terminado: Don Juan, después de los años y tras varios fracasos, regresa a casa pidiendo el perdón de Elvira, su mujer, pero ésta le rechaza.

16 Desde el drama fundacional, en cada una de las burlas, don Juan pide o da la mano a su víctima como prueba de la palabra empeñada $y$, como sabemos, nunca lo cumple, siempre engaña. También, en la segunda parte de la obra, la que gira en torno al convidado de piedra, se emplea este gesto en señal de compromiso, aunque ahora es el Convidado quien la solicita. Pues bien, igual que el héroe, también el muerto incumple su palabra y aprovecha la confianza que en él deposita don Juan para matarle y arrastrarle al fuego eterno del in- 
fierno. Así pues, "dar la mano" puede ser interpretado como un motivo estructural que relaciona indisolublemente al amor y la muerte. Tal vez, el conocimiento de la existencia de este motivo en la tradición donjuanesca, motivo que mantiene Molière, sea la causa de la disposición de los elementos en el encuadre en el plano referido del film de Weber.

\section{BIBLIOGRAFÍA}

Becerra, Carmen (1997): Mito y Literatura. Estudio comparado de Don Juan, Vigo, Universidad de Vigo.

- y Carmen Luna (eds.) (2008): Teatro y Cine, Vigo, Academia Editorial del Hispanismo.

Bobes Naves et al. (2002): Nuevas Perspectivas en Semiología Literaria, Madrid, Arco/Libros.
Brunel, Pierre (1999): Dictionaire de Don Juan, Paris, Robert Laffont.

Gerard Defaux (1980): Molière ou les metamorphoses du comique. De la comédie morale au triomphe de la folie, Kentucky, French Forum Publishers, Lexington.

Doležel, Lubomir (1986): "Semiotics of Literary Communication", Strumenti Critici, 1, pp. 5-48. Traducción española de Fernando Romo, "Semiótica de la comunicación literaria", en Bobes Naves et al., pp. 173-218.

Feal, Carlos (1984): En nombre de don Juan (Estructura de un mito literario), Philadelphia, John Benjamin Publishing Company.

Fernández, Luis Miguel (2000): Don Juan en el cine español. Hacia una teoría de la recreación fílmica, Santiago de Compostela, Servicio de publicaciones de la Universidad de Santiago.
Guicharnaud, Jacques (1963): Molière, une aventure théâtrale, Paris, Gallimard.

Hoffmann, E.T.A. (1986): Fantasías a la manera de Callot, Madrid, Anaya.

Horville, Robert (1972): Dom Juan de Molière (une dramaturgie de rupture), Paris, Larousse Université.

Macchia, Giovanni (1978): Vita, Avventure e Morte di Don Giovanni, Torino, Piccola Biblioteca Einaudi.

Molière (1980): Tartufo. Don Juan o El Convidado de piedra, traducción por Carlos M. Princivalle y A. Cebrián, Madrid, Espasa-Calpe.

Rousset, Jean (1978): Le mythe de Don Juan, Paris, Librairie Armand Colin.

Sellier, Philippe (1984): "Qu'est-ce qu'un mythe littéraire?", en Littérature, n. 55.

Villanueva, Dario (2008): "La transformación de la obra literaria: Los Macbeth de Roman Polanski y de Harold Bloom", en Carmen Becerra y Carmen Luna (eds.) (en prensa). 